\title{
Analysis and Optimization Study of Piston in Diesel Engine Based on ABC-OED-FE Method
}

\author{
Qi Jing, Yi Dong $\mathbb{D}^{\mathbb{D}}$, Jianmin Liu, Huaying Li $\mathbb{D}$, Yanbin Liu $\mathbb{D}$, and Shaoliang Zhang
}

Vehicle Engineering Department, Army Academy of Armored Forces, Beijing 100072, China

Correspondence should be addressed to Huaying Li; ss_sw_love@126.com

Received 29 July 2020; Revised 2 January 2021; Accepted 13 January 2021; Published 30 January 2021

Academic Editor: David Bigaud

Copyright (C) 2021 Qi Jing et al. This is an open access article distributed under the Creative Commons Attribution License, which permits unrestricted use, distribution, and reproduction in any medium, provided the original work is properly cited.

\begin{abstract}
In order to increase the reliability and service life of piston in a heavy-duty diesel engine, the geometric structure of piston was optimized based on its maximum temperature and maximum coupling stress. To begin with, the boundary conditions of thermal and stress fields are calculated, which include the heat produced by the combustion in cylinder, the friction-induced heat, and the heat transferred to cooling system. Then, the finite element model was established to calculate and analyse the temperature and thermal-mechanical coupling stress fields of the piston. By combining this simulation model with orthogonal experimental design methods, computations and analyses were performed to determine how the five geometric parameters (depth of intake and exhaust valve grooves, radius of valve grooves transition, radius of top of valve grooves, height of first piston ring groove, and depth of piston ring groove) influence the two evaluation indicators (maximum temperature and maximum stress of piston). Subsequently, using the proposed ABC-OED- FE (artificial bee colony, orthogonal experiment design, and fitting equations) method, the fitting equations between the geometric parameters and evaluation indicators were determined. Taking the minimum values of two evaluation indicators of piston as optimization objectives, artificial bee colony method was run to determine the values of parameters. At last, the two evaluation indicators of the optimized piston were computed. The results indicate that, after optimization, the maximum temperature of piston decreases to be $16.05 \mathrm{~K}$ and the maximum stress decreases to be $13.54 \mathrm{MPa}$. Both temperature and stress conditions of the optimized piston had been improved, which demonstrates the effectiveness of the optimization and the validity of the algorithm.
\end{abstract}

\section{Introduction}

With development of science and technology, the power density of diesel engine increases continuously. As a result, the thermal load and mechanical load exerted on high temperature components in engine's cylinders, especially pistons, have also been increased. According to the results of simulation analysis [1], when a heavy-duty diesel engine works under plateau conditions, thermal-mechanical coupling stress can rise up to $167 \mathrm{MPa}$. Prolonged operation under such an environment may cause interior fatigue damage to pistons and even lead to creep fatigue failure. Coupling effect of fatigue and creep would drastically shorten the service life of piston and other high temperature components and severely influence the reliability of the entire engine.
Ample research has been conducted in view of such situation. Combustion condition in cylinder can provide the boundary conditions to calculate the thermal stress field and the thermal-mechanical coupling stress field of piston. It is necessary to analyse the combustion before studying the piston temperature field. Cihan et al. [2] analysed effect of three different types of combustion chamber on the combustion condition. Results show that the $M$ combustor has the best combustion factor and there are some other measures needed to be taken to improve the combustion performance. Wang et al. [3] studied the relationship between compression ratio and ignition type of diesel. Results reveal that, to improve the quality of combustion, the ignition time should be advanced and that flammability limits should be extended. Yuan et al. [4] established a coupling model to simulate the combustion character of a free piston 
engine generator. Results show that the free piston engine has a longer combustion duration and that the average pressure and temperature in cylinder are generally lower than the common engine. Khan et al. [5] studied the effect of piston geometry and other parameters on the combustion of engine. They established the combustion computational fluid dynamics model using the software of AVL-FIRE. The different geometries of piston are toroidal reentrant combustion chamber (TRCC), toroidal combustion chamber (TCC), and the baseline hemispherical combustion chamber (HCC). Results show that TRCC is better than other chambers. Geng et al. [6] realized a dual assisted compression ignition combustion (DACIC) engine, which made the authors have more controllability on the combustion process. Results show that the DACIC has a wider compression ratio range. There are also some researches considering combustion chamber [7], combustion stability [8], combustion characteristics [9], and so on [10].

For the piston temperature field, another important heat source is the friction heat. Besides, the frictional condition between piston and the cylinder liner can also affect the dynamic performance of the engine. Therefore, it is important for the study of the friction. Boru Jia et al. [11] researched and compared the different friction mechanisms of free piston engines (FPE) and crankshaft engines (CSE). The detailed content of the friction includes the piston ring friction characteristics, piston skirt friction characteristics, value train friction characteristics, and the crank and bearing friction characteristics for the CSE. Results show that, compared to the CSE, the FPE do not have obvious advantage in friction characteristics. In order to realize the accurate and real time measurement of the frictional condition of piston, Fang et al. [12] come up with an improved measurement technique. Results show that the improved measurement system is accurate and reliable compared with the original one. Söderfjäll et al. [13] studied the frictional condition in diesel engine under different variables, such as different piston ring designs, different cylinder liner roughness, and different grade oil. With the experiment data, they established a simulation model to analyse the friction condition of the piston. There are also some researches focusing on frictional losses [14], lubricating oil transport between piston and cylinder liner [15], experiment study of friction [16], and so on.

In order to improve the working state of piston and the engine, many researchers studied the optimization method to reduce the heat and mechanical load of the piston. $\mathrm{Xu}$ et al. [17] simulated the piston of a new cam type engine using finite element method. By combining the calculation results, optimization and improvement proposals were presented, which is to install thermal insulation screws on the piston. Simulation results show that both temperature and deformation of the optimized piston dropped down to a certain extent. Wang et al. [18] conducted analysis on the temperature and stress fields of the marine diesel piston with established finite element model. The frictional wear of the piston was analysed by combining relevant models before a series of optimization suggestions were proposed. The validity of optimization was verified through tests. Zhaoju et al.
[19] studied the corresponding relationship among "height of the piston's top," the "holes on piston pin," "weight of piston," and "maximum temperature of piston," "maximum mechanical stress," and "maximum thermal-mechanical coupling stresses" by adopting experimental design methods. The weight of piston and maximum coupling stress were optimized based on the calculation results. Zhang et al. [20] compared and studied the influence rule of $\omega$-shaped, wave-shaped top of piston on the combustion of blended fuel, and the performance of diesel engine. Results show that the wave-shaped top of piston performed better in improving the combustion efficiency and reduction of exhaust emission. Sadiq and Iyer [21] studied the influence rule of the compression ratio, shape of piston's top on fuel combustion, and engine performance. The results indicate that large cleavage piston and the bigger compression ratio can improve the performance of the engine. There are also some researches focusing on the dynamic modelling and parameters optimization of piston [22], effects of different piston bowl [23], multiobjective optimization of piston using response surface methodology [24], and so on [25-27].

The literatures above revealed the following problems about the current research direction of pistons: (1) existing studies rarely involved pistons in heavy-duty diesel engine; these pistons generally work in harsh environment conditions and easily suffer the damage of fatigue failure and hence should be given more attention; (2) when calculating and analysing the temperature and stress fields of piston, not all of the boundary conditions were considered; e.g., problems such as heat produced from friction between the piston ring set and the cylinder liner were not considered in most of literatures; (3) optimizations of the geometric structures of piston were merely empirical or only aimed at a single variable, and the interactions between different factors were not considered, which caused the lack of theoretical support and appropriate cogency.

The main aim of the study is based on the working status and temperature and stress conditions to optimize the geometry of piston to alleviate the working state of piston. On the basis of relevant studies and in combination with the maximum temperature and maximum stress of piston, this paper discusses the optimization of the $3 \mathrm{D}$ geometric structure of the piston. During calculation of the temperature and stress fields of piston, boundary conditions, such as the heat produced by combustion, heat produced by friction, and heat dissipated to coolant system, were considered. In addition, during the optimization process, the orthogonal experimental design (OED) method and the artificial bee colony (ABC) algorithm were adopted, which made the optimization process more scientific and the optimization results more reliable. The main work of this paper includes the following parts. In the first part, boundary conditions for calculating the temperature and stress fields of piston were analysed, which include heat produced by combustion, heat produced by friction between the piston ring set and cylinder liner, heat dissipated to the coolant system, and mechanical force exerted on the piston. In the second part, the temperature field and thermal-mechanical coupling stress field of the piston were analysed using the 
boundary condition and the established finite element model; the calculation results were verified with tests. In the third part, based on the constraints and objectives of the optimization, 5 geometric parameters to be optimized were defined. The influencing rule of these parameters on two indicators (maximum temperature and maximum stress of piston) was calculated and analysed in detail using OED method. In the fourth part, the corresponding relationship between the optimization parameters and evaluation indicators was established using the proposed ABC-OED-FE method, and the optimal geometric parameters of the piston were determined. In the fifth part, the temperature and stress fields of the optimized piston were calculated and analysed, which verified the effectiveness of the optimization and the validity of the algorithm.

\section{Boundary Conditions of Piston Temperature and Stress Fields}

2.1. Heat Produced by Combustion. In order to calculate and analyse the temperature and stress fields of the piston in detail, the combustion process model of diesel engine [28] was established to calculate and analyse the boundary conditions of the fields. Through calculation, the variation trend of temperature and heat transfer coefficient of gas in cylinder with the change of crank angle was obtained and is as shown in Figure 1.

In order to verify the accuracy of the calculation model and results, bench tests were conducted to measure such parameters as power and torque of the diesel engine. The measured values were then compared with the calculated values. The configuration of the test bench is shown in Figure 2. It is a device used to determine the state of combustion in the diesel engine and measure the parameters of the gas in the cylinder [29]. The test system is mainly made up of several parts, including computer control system, diesel and its start moto, output dynamo meter, diesel combustion analysis system, and system control unit. System control unit can control the whole lab, measure the data by sensor, and process the results. Diesel and its start moto are the object of this study and the core part of the lab. Output dynamo meter can measure the state parameters of the diesel. Diesel combustion analysis system can measure the variation of evaluation indicators of engine by adjusting the inlet value, exhaust value, and the oil atomizer. $P_{1}, P_{2}$, and $P_{3}$ are core components of the control unit system to adjust the oil atomizer, exhaust value, and inlet value. The temperature of combustion air is measured by the sensor in the system.

The detailed information of lab is shown in Table 1.

The comparison between the model's calculation results and those acquired through the experiments for the operation process of the diesel engine is shown in Table 2.

As indicated by the table, errors between the experiment results and calculation results are all minus $6 \%$, and hence have fulfilled the requirements of engineering calculation. This shows that the established simulation model for the operation process of diesel engine is rather accurate and can

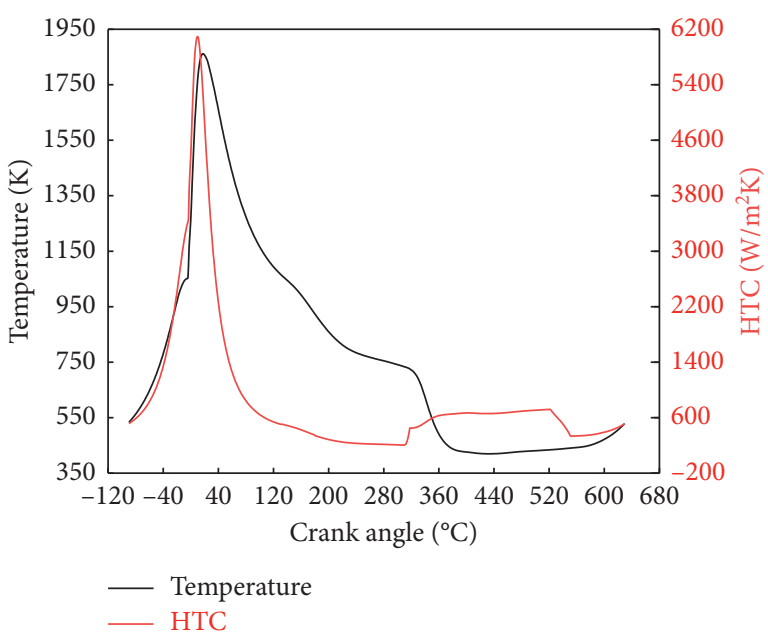

Figure 1: Variation trend of temperature and heat transfer coefficient of gas in cylinder.

be used for subsequent studies of thermal environment of the piston.

2.2. Frictional Heat. The derivative of piston displacement equation was solved to obtain the speed equation [30]. And it can be expressed as a compound harmonic function consisting of two sinusoidal functions with different rates of change [31]. The position of the piston relative to the top dead point and its speed with the variation of crank angle, as obtained from above equations, are shown in Figure 3.

Figure 4 displays the temperature change when piston is at different positions away from the top dead point. The figure shows that the magnitude of temperature rise is closely related to the speed of piston ring. When the piston moves to the middle of the cylinder liner, the rate of temperature change reaches the maximum, and so does the speed of piston. In addition, the figure also indicates that while the piston assembly moves from top dead point to bottom dead point, the frictional heat keeps accumulating, causing the temperature to rise as high as $8.67 \mathrm{~K}$ solely because of the friction heat.

2.3. Cooling and Heat Dissipation. Since the lubrication oil between the piston and cylinder liner mainly serves the purpose of lubrication, it was taken as thermal resistance during the calculation and analysis [32]. In this paper, only the lubrication oil in the piston's cavity and the surface of cylinder liner was considered. For diesel engine, the cooling of the piston's cavity was done through splash lubrication of oil; the coefficient of heat transfer was then calculated using the following equation [33]:

$$
h_{\mathrm{oil}}=\frac{t_{1}-t_{2}}{t_{2}-t_{w}} \cdot \frac{\lambda}{\delta}
$$

where $t_{1}, t_{2}$, and $t_{\mathrm{w}}$ are temperatures of gas in cylinder, piston top, and wall of piston's top, respectively; $\lambda$ is heat conductivity of piston; $\delta$ is the thickness of the piston's top. 


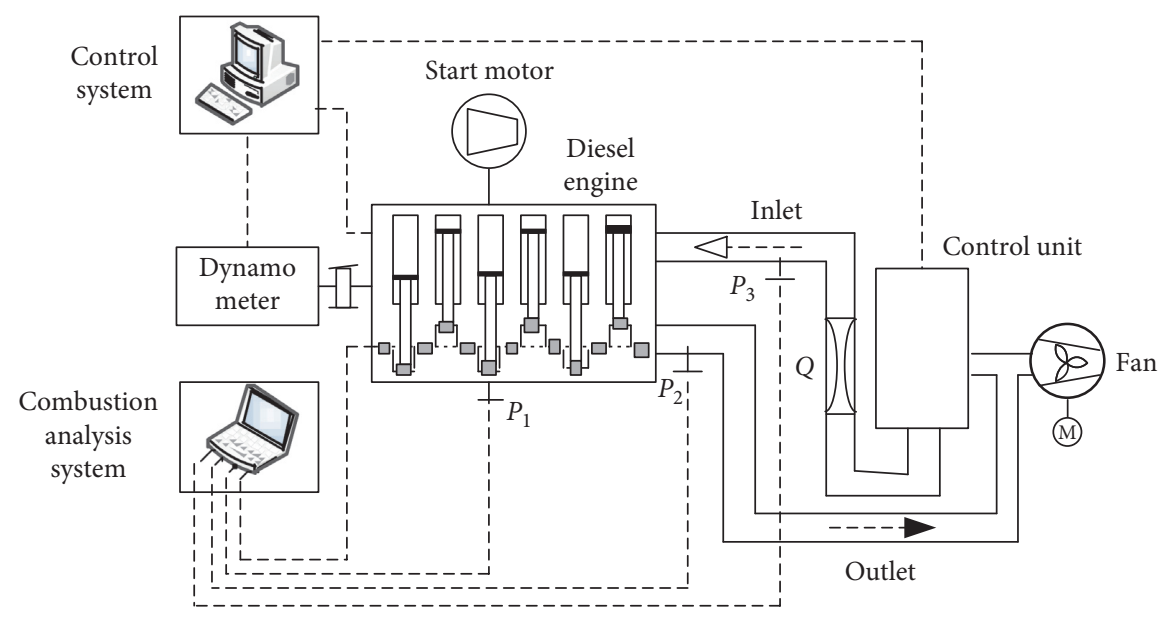

Figure 2: Schematic diagram of the bench test.

TABLE 1: The detailed information of lab.

\begin{tabular}{lcc}
\hline Device & Specification & Accuracy \\
\hline Output dynamo meter & QZTI-QZ1030 & $<0.1 \mathrm{~kW}<0.01 \mathrm{Nm}$ \\
Diesel analysis system & LUBO-3010 & $<0.1 \mathrm{~K}<0.1 \mathrm{~Pa}$ \\
$P_{1}$ & WT31820 & $<1 \mathrm{mg}$ \\
$P_{2}$ & DS18B20 & $<0.1 \mathrm{~K}$ \\
$P_{3}$ & DS18B20 & $<0.1 \mathrm{~K}$ \\
Fan & XN-1-2740 \\
Temperature control unit & OMRON CJ1W-TC001 & $<0.1 \mathrm{~K}$ \\
Humidity control unit & KZP-5-CA & $<0.1 \%$ \\
\hline
\end{tabular}

TABLE 2: Comparison between the calculated and experimental values of diesel engine.

\begin{tabular}{cccccc}
\hline Speed & Experiment & $\begin{array}{c}\text { Power }(\mathrm{kW}) \\
\text { Calculation }\end{array}$ & Error (\%) & Experiment & $\begin{array}{r}\text { Torque (Nm) } \\
\text { Calculation }\end{array}$ \\
\hline 1400 & 463 & 475.8 & 2.82 & 3255.57 & 3245.30 \\
1600 & 525 & 518.6 & -1.24 & 3205.44 & 3095.07 \\
1800 & 570 & 558.5 & -2.15 & 3152.88 & 2969.84 \\
2000 & 588 & 594.7 & 1.11 & 2816.31 & 2839.40 \\
\hline
\end{tabular}

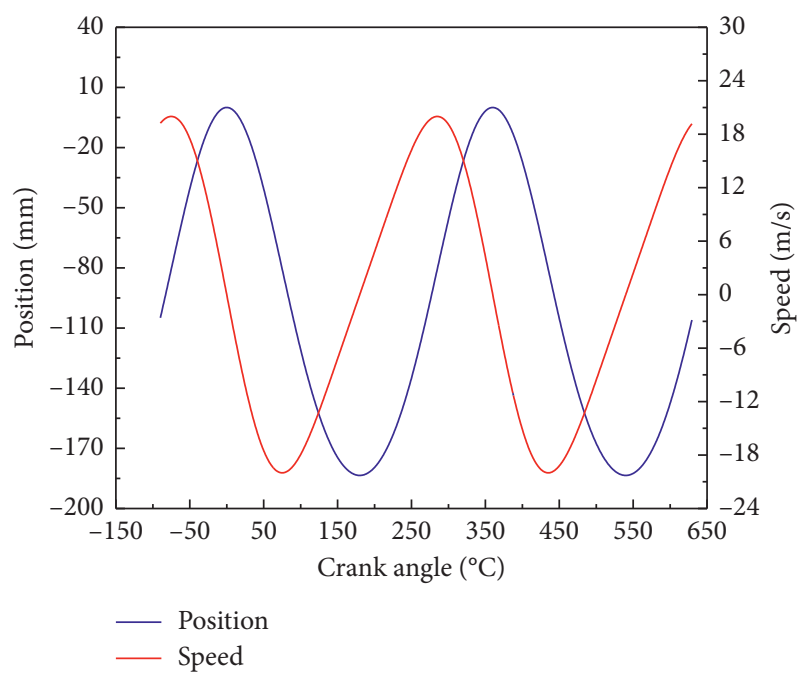

Figure 3: Variation of piston position and speed.

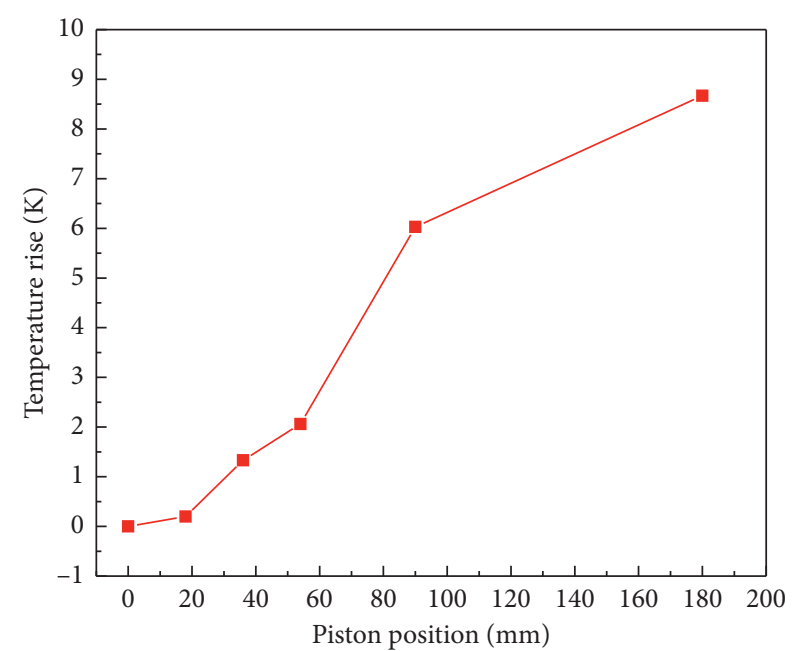

Figure 4: Temperature rise in different piston positions. 
2.4. Mechanical Force. This study mainly focused on the piston temperature and thermal-mechanical stress field under rated operating conditions. The analysis on the mechanical boundary conditions is as follows. Throughout the operation, the forces exerted on the piston are as follows: $F_{c}$ is pressure of gas explosion in cylinder; $F_{n}$ is side thrust; $F_{g}$ is inertia force due to reciprocating motion and $F_{x}$ is counterforce of piston pin. The value of mechanical force exerted on the piston is calculated at the moment that the cylinder pressure is at its maximum value. The mass of the piston was $2.58 \mathrm{~kg}$, and the calculation of the forces exerted on the piston is shown in Table 3. In the table, $p_{c}$ indicates the maximum explosion pressure in the cylinder.

\section{Temperature and Stress Fields of the Piston}

3.1. Simulation Model. This paper took the piston of a 12 cylinder four-stroke turbocharged diesel engine as the object of study [34]. To analyse and calculate its temperature and thermal-mechanical coupling stress fields under rated operating conditions, the authors established a three-dimensional geometric model for the piston, as shown in Figure 5.

The model was meshed and generated 316,651 nodes and 190,148 elements eventually. The meshing model is shown in Figure 6.

3.2. Boundary Conditions. Boundary conditions of temperature and thermal-mechanical coupling stress fields of piston can be obtained from the work of the first part in this article. During calculation, we divided the surface of piston into 17 separate zones and applied the heat transfer boundary conditions to the different zones. The values of the boundary conditions are illustrated in Table 4 .

We can get the temperature and thermal stress fields of piston using the model and boundary conditions. Combining the thermal stress field with mechanical stress's boundary conditions, we can get the thermal-mechanical coupling stress field finally.

3.3. Result Verification and Analysis. The temperature field of the piston obtained from calculation was verified via experiments with the hardness plugs. The arrangement of test points is shown in Figure 7, which is a profile map across its axes.

The hardness plugs used in this article are cylindrical plugs with the geometry dimension of $1.9 \mathrm{~mm}$ radius and $5.6 \mathrm{~mm}$ length. The detailed parameters of hardness plug are shown in Table 5.

The fitted equation of hardness plug is

$$
T_{p}=-1.11108 H_{p}+999.73,
$$

where $T_{p}$ is the temper temperature of hardness plug. $H_{p}$ is the value of Vickers hardness after temper.

The test points in experiment are shown in Figure 8

Table 6 shows the comparison between the calculated and experimental values of the piston.

It can be seen from Table 5 that the errors between the calculated and experimental values were minus $5 \%$, which
TABLE 3: Values of the forces.

\begin{tabular}{lc}
\hline Forces & Values \\
\hline$\left(p_{c} / \mathrm{bar}\right)$ & 102.7 \\
$\left(\mathrm{~F}_{c} / \mathrm{kN}\right)$ & 179.7 \\
$\left(F_{g} / \mathrm{kN}\right)$ & 45.1 \\
$\left(F_{x} / \mathrm{kN}\right)$ & 134.7 \\
$\left(F_{n} / \mathrm{kN}\right)$ & 5.6 \\
\hline
\end{tabular}

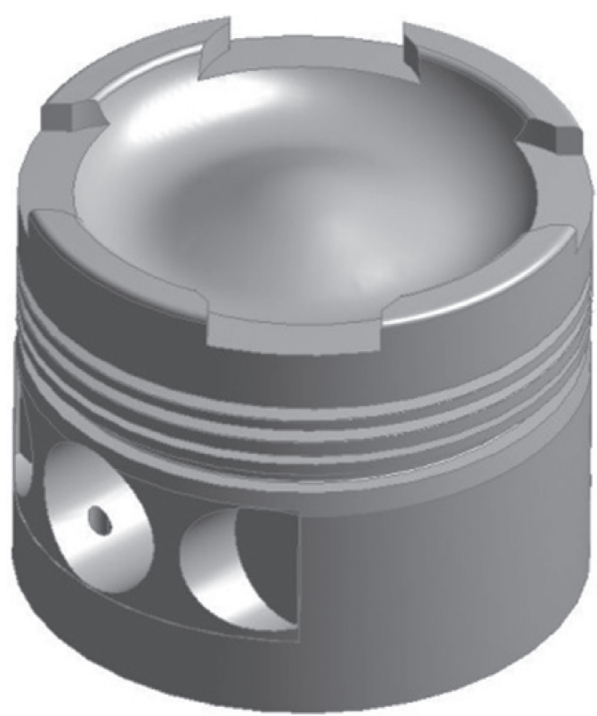

Figure 5: Three-dimensional geometric model of the piston.

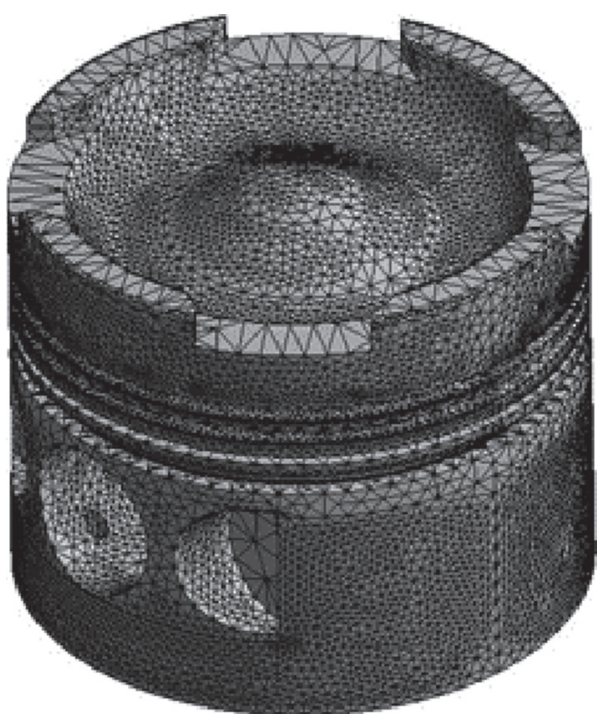

Figure 6: Meshing model of the piston.

demonstrates the accuracy of the simulation, and hence can be deemed as having fulfilled the engineering requirements.

Figure 9 displays the temperature field of piston. According to the figure, the maximum temperature of the piston was $623.67 \mathrm{~K}$ which occurred at the inner circle in piston top, while the minimum temperature was $364.17 \mathrm{~K}$, which occurred at the piston skirt. The temperature difference between maximum and minimum value was $259.5 \mathrm{~K}$. From top to down, the value 
TABLE 4: Boundary conditions for calculation of piston temperature field.

\begin{tabular}{|c|c|c|c|}
\hline Zones & & Temperature $(\mathrm{K})$ & Heat transfer coefficient $\left(\mathrm{W} / \mathrm{m}^{2} \mathrm{~K}\right)$ \\
\hline \multirow{3}{*}{$\omega$-type groove in piston top } & Inner circle & & 887 \\
\hline & Middle circle & & 864 \\
\hline & Outer circle & 679 & 836 \\
\hline \multirow{2}{*}{ The highest area in piston top } & Inlet and outlet groove & & 864 \\
\hline & Other areas & & 887 \\
\hline The first junk of piston & & 560 & 680 \\
\hline The first groove of piston ring & & 415 & 2152 \\
\hline Second junk of piston & & 410 & 478 \\
\hline Second groove of piston ring & & 408 & 1759 \\
\hline Third junk of piston & & 403 & 438 \\
\hline Third groove of piston ring & & 397 & 1405 \\
\hline Fourth junk of piston & & 390 & 457 \\
\hline Piston skirt & & 380 & 400 \\
\hline Piston pin hole & & 380 & 400 \\
\hline \multirow{3}{*}{ Piston cavity } & Top & & 887 \\
\hline & Middle & 370 & 745 \\
\hline & End & & 605 \\
\hline
\end{tabular}

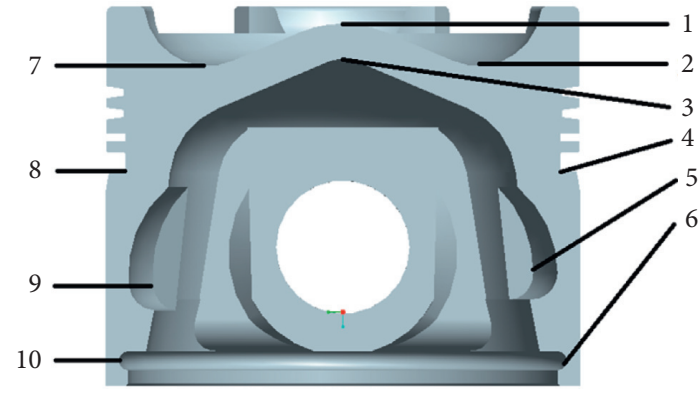

Figure 7: Arrangement of the test points.

TABLE 5: Detailed parameters of hardness plug.

\begin{tabular}{lc}
\hline Parameters & Values \\
\hline Type & HXD $-1000 \mathrm{TMC}$ \\
Location error & $<2 \mu \mathrm{m}$ \\
Range of measurement & $5-3000 \mathrm{HV}$ \\
Minimum counting unit & $0.01 \mu \mathrm{m}$ \\
Minimum measurement unit & $0.025 \mu \mathrm{m}$ \\
Error & $<3 \%$ \\
Government standard & $\mathrm{GB} / \mathrm{T} 4340$ \\
\hline
\end{tabular}

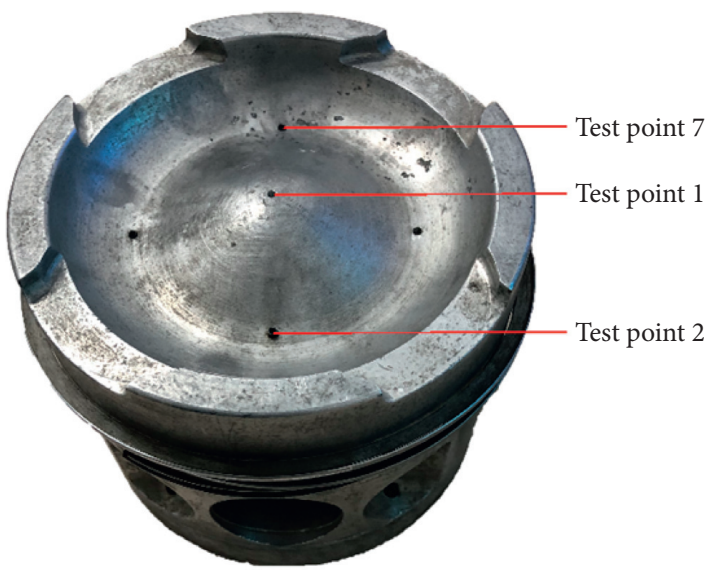

Figure 8: Arrangement of the test points in experimental piston. of temperature along the axis of piston was decreasing gradually. The temperatures at the edge of the intake and exhaust valve grooves were high enough to cause erosion and fatigue damage and shall be taken seriously.

Figure 10 shows the distribution of thermal-mechanical coupling stress field of piston under the maximum cylinder pressure.

According to the figure, the maximum stress exerted on the piston was $168.67 \mathrm{MPa}$, which occurred at the location between the pin circle and the first ring groove, while the minimum stress was $359 \mathrm{KPa}$, which occurred at the piston skirt. Since most of the piston heat transferred to the coolant was through the ring and the pin circle was forced to withstand concentrated mechanical force, the maximum stress of piston occurred at the area located between piston pin circle and ring grooves. At the same time, fatigue damage is highly likely to occur in this area, and more attention shall hence be paid there to.

According to Figures 9 and 10, there are two areas in the piston that are at serious condition and are prone to fatigue failure. So, in the next part of article, we will use some methods and algorithms to optimize these two areas in piston, trying to reduce the thermal and mechanical load, and increase its reliability and fatigue life.

\section{Calculation and Analysis Based on Orthogonal Experiment}

Results from above calculation and analysis showed that the maximum temperature of piston occurs near the intake and exhaust valve grooves, while the maximum stress of piston appeared near the piston ring grooves. In view of this, the optimization was prioritized for both these positions, i.e., intake and exhaust valve grooves at piston top, as well as the first piston ring groove.

4.1. Constraint Conditions for the Optimization. The following constraint conditions [35] were determined based on 
TABLE 6: Comparison between the calculated and experimental values of the piston.

\begin{tabular}{lcccccccccc}
\hline Test points & 1 & 2 & 3 & 4 & 5 & 6 & 7 & 8 & 9 \\
\hline Calculation value & 629.2 & 562.0 & 572.3 & 523.0 & 493.4 & 493.8 & 588.5 & 539.8 & 504.3 & 490.4 \\
Experiment value & 621.6 & 580.8 & 558.7 & 530.3 & 483.7 & 479.3 & 582.3 & 533.5 & 482.9 & 480.3 \\
Error/\% & 1.21 & -3.34 & 2.38 & -1.39 & 1.97 & 2.95 & 1.05 & 1.16 & 4.25 & 2.06 \\
\hline
\end{tabular}

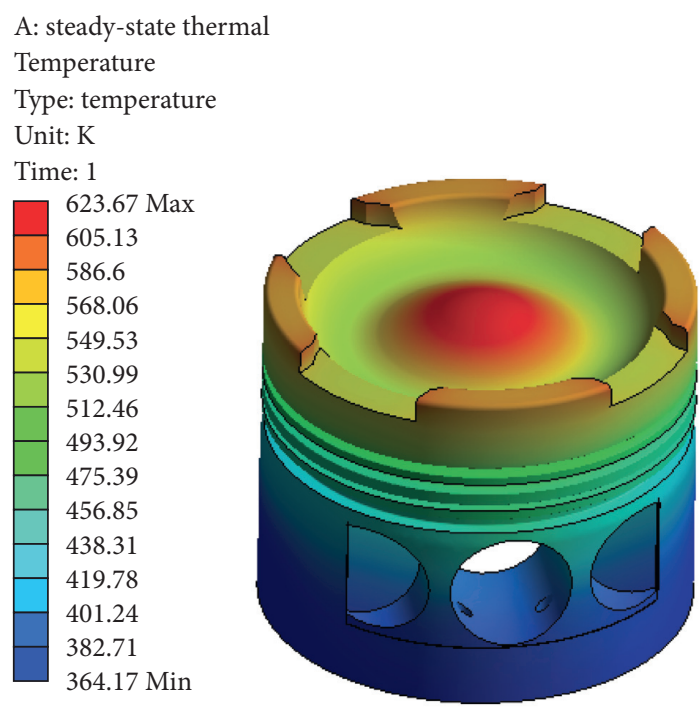

FIgURE 9: Distribution of temperature field of piston.
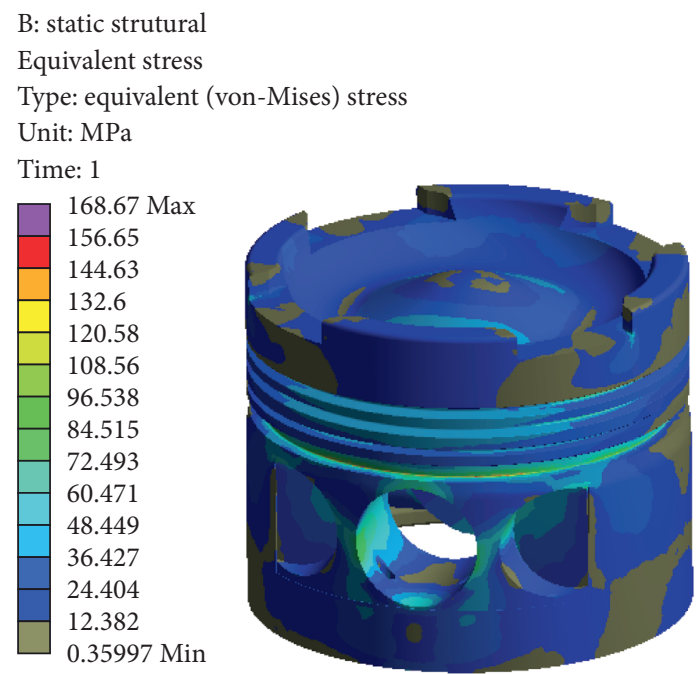

FIGURE 10: Thermal-mechanical coupling stress field of the piston.

the analysis of calculation results in combination with the real operating conditions:

(1) The overall piston dimensions shall be unchanged and the postoptimized piston shall be able to prevent it from colliding with such components as the cylinder head, valves, and connecting rod

(2) The difference in the total masses between the piston before and after optimization shall be minus 5\%, which is in order to prevent the excessive influence on piston's interaction with the cylinder liner and connecting rod due to the optimization

(3) The difference of engine's displacements between the piston before and after optimization shall be minus $5 \%$ in order to prevent excessive influence on the combustion process due to the optimization

(4) The piston's optimization shall exert no influence on the functioning of itself and that of other parts in the diesel engine

4.2. Objectives of the Optimization. Based on the calculation and analysis above, optimizations on the following 5 parameters were determined by considering the constraints and real operation conditions of diesel engine.

(1) $h_{g}$, depth of intake and exhaust valve grooves, was to be adjusted while maintaining overall dimensions of the piston. Initial value of $h_{g}$ is $6 \mathrm{~mm}$.

(2) A smooth transition to the bottom of intake and exhaust valve grooves was to be added, without impacting the opening and closing of intake and exhaust valves. The radius of curvature was assumed to be $r_{b}$.

(3) A smooth transition to the top of piston intake and exhaust valve grooves was to be added, without impacting the opening and closing of intake and exhaust valves. The radius of curvature was assumed to be $r_{t}$.

(4) $h_{r}$, the height of first piston ring groove, was to be adjusted (the height of connecting area between grooves shall also be adjusted to maintain overall dimensions of piston). The initial value of $h_{r}$ is $2.5 \mathrm{~mm}$

(5) $d_{r}$, the depth of piston ring grooves, was also to be adjusted. The initial value of $d_{r}$ is $6 \mathrm{~mm}$.

By considering actual conditions, 5 different levels of the 5 parameters to be optimized are as shown in Table 7.

4.3. Test Process and Results. The aim of the study is to decrease the thermal and mechanical load by optimizing the 5 piston parameters. So, the evaluation indicators of the optimization are the state indicators of piston: maximum temperature $T_{\max }$ and maximum stress $S_{\max }$.

The orthogonal experiment design method can figure the influence rules of 5 piston parameters on the evaluation indicators out fast and accurately, which could find the most valuable parameters using the minimum experiments sets. Therefore, the effect of 5 optimization parameters on the 2 evaluation indicators of piston was studied using orthogonal 
TABLE 7: Different levels of the 5 parameters to be optimized ( $\mathrm{mm}$ ).

\begin{tabular}{lccccc}
\hline Parameters & Level I & Level II & Level III & Level IV & Level V \\
\hline$h_{g}$ & 5.6 & 5.8 & 6 & 6.2 & 6.4 \\
$r_{b}$ & 2.1 & 2.3 & 2.5 & 2.7 & 2.9 \\
$r_{t}$ & 2.1 & 2.3 & 2.5 & 2.7 & 2.9 \\
$h_{r}$ & 2.3 & 2.4 & 2.5 & 2.6 & 2.7 \\
$d_{r}$ & 5.8 & 5.9 & 6 & 6.1 & 6.2 \\
\hline
\end{tabular}

experiment design (OED) method [36]. According to Table 5 , it is an orthogonal experiment consisting of 5 parameters and 5 levels. In view of this, an orthogonal experiment table $L_{25}\left(5^{6}\right)$ with 6 factors and 5 levels was used. The maximum temperature $T_{\max }$ and maximum stress $S_{\max }$ of piston were calculated with finite element model established in part 1 . The experiment arrangements and corresponding results are shown in Table 8 .

4.4. Results' Analysis. The calculation results for each level and indicator are summarized in Table 9.

The equations for calculating the variables in the table are as follows [37]:

$$
\begin{aligned}
A_{i} & =\sum_{j=1}^{5} a_{i j}, \\
S_{i}^{2} & =\sum_{i=1}^{5} \frac{A_{i}^{2}}{n_{s}}-\left(\frac{\left(\sum_{j=1}^{5} a_{i j}\right)^{2}}{n_{t}}\right), \\
R & =A_{\max }-A_{\min },
\end{aligned}
$$

where $\mathrm{A}_{i}$ is the sum of indicators (maximum temperature of piston $T_{\max }$ or maximum stress of piston $S_{\max }$ ) corresponding to level $i ; a_{i j}$ is the value of indicators corresponding to parameter $i$ and level $j ; S_{i}^{2}$ is the sum of square of columns' change which indicates overall variation of the observed values; in this article the number of parameters is 5 ; $n_{s}$ is the number of levels and its value is $5 ; n_{t}$ is total number of data and its value is $25 ; A_{\max }$ is the maximum value among $A_{i}$ under current parameter; $A_{\min }$ is the minimum value among $A_{i}$ under current parameter; $R$ is the difference between $A_{\max }$ and $A_{\min }$, which indicates the effect degree of corresponding parameter.

The significance test and variance analysis were performed for each parameter, and the results are as shown in Table 10.

The method for calculating the degree of freedom of the parameters is as follows:

$$
f_{d}=n_{s}-1=4
$$

Analysing Tables 9 and 10, it can be seen that the rounded corners $r_{b}$ and $r_{t}$ at the bottom and top of the intake and exhaust valve grooves exerted a significant effect on the maximum temperature of piston $T_{\max }$, wherein the rounded corner $r_{b}$ at the bottom showed the highest significance; height $h_{r}$ and depth $d_{r}$ of the first ring groove exerted a
TABLE 8: Test arrangement and calculation results of OED.

\begin{tabular}{lccccccc}
\hline Number & $h_{g}$ & $r_{b}$ & $r_{t}$ & $h_{r}$ & $d_{r}$ & $T_{\max }$ & $S_{\max }$ \\
\hline 1 & 5.6 & 2.1 & 2.1 & 2.3 & 5.8 & 625.140 & 165.107 \\
2 & 5.6 & 2.3 & 2.3 & 2.4 & 5.9 & 629.941 & 203.957 \\
3 & 5.6 & 2.5 & 2.5 & 2.5 & 6.0 & 620.375 & 165.744 \\
4 & 5.6 & 2.7 & 2.7 & 2.6 & 6.1 & 621.527 & 180.359 \\
5 & 5.6 & 2.9 & 2.9 & 2.7 & 6.2 & 617.251 & 151.055 \\
6 & 5.8 & 2.1 & 2.3 & 2.5 & 6.1 & 633.482 & 154.066 \\
7 & 5.8 & 2.3 & 2.5 & 2.6 & 6.2 & 624.462 & 175.279 \\
8 & 5.8 & 2.5 & 2.7 & 2.7 & 5.8 & 622.167 & 154.699 \\
9 & 5.8 & 2.7 & 2.9 & 2.3 & 5.9 & 625.264 & 189.055 \\
10 & 5.8 & 2.9 & 2.1 & 2.4 & 6.0 & 615.824 & 164.961 \\
11 & 6.0 & 2.1 & 2.5 & 2.7 & 5.9 & 631.962 & 185.224 \\
12 & 6.0 & 2.3 & 2.7 & 2.3 & 6.0 & 627.531 & 166.363 \\
13 & 6.0 & 2.5 & 2.9 & 2.4 & 6.1 & 619.856 & 171.368 \\
14 & 6.0 & 2.7 & 2.1 & 2.5 & 6.2 & 625.567 & 152.161 \\
15 & 6.0 & 2.9 & 2.3 & 2.6 & 5.8 & 633.521 & 182.215 \\
16 & 6.2 & 2.1 & 2.7 & 2.4 & 6.2 & 635.168 & 158.030 \\
17 & 6.2 & 2.3 & 2.9 & 2.5 & 5.8 & 623.249 & 161.857 \\
18 & 6.2 & 2.5 & 2.1 & 2.6 & 5.9 & 621.284 & 202.763 \\
19 & 6.2 & 2.7 & 2.3 & 2.7 & 6.0 & 630.517 & 150.509 \\
20 & 6.2 & 2.9 & 2.5 & 2.3 & 6.1 & 619.842 & 152.142 \\
21 & 6.4 & 2.1 & 2.9 & 2.6 & 6.0 & 630.850 & 152.442 \\
22 & 6.4 & 2.3 & 2.1 & 2.7 & 6.1 & 622.847 & 153.901 \\
23 & 6.4 & 2.5 & 2.3 & 2.3 & 6.2 & 629.419 & 150.716 \\
24 & 6.4 & 2.7 & 2.5 & 2.4 & 5.8 & 625.861 & 159.885 \\
25 & 6.4 & 2.9 & 2.7 & 2.5 & 5.9 & 625.617 & 183.147 \\
\hline
\end{tabular}

significant effect on the maximum stress of piston $S_{\max }$, wherein depth $d_{r}$ of the first ring groove showed the highest significance. Since the results obtained were a group of discrete points, optimal parameters of the piston could hardly be determined merely based on results from the orthogonal experiment. In view of this, based on above calculation, a method for optimizing the piston parameters on the basis of $\mathrm{ABC}$ and fitting of polynomials was proposed to solve the problem.

\section{ABC-OED-FE Based Piston Parameters Optimization}

5.1. ABC Algorithm. Artificial bee colony (ABC) algorithm [38] is a calculation method presented by Karaboga based on the behaviour of foraging nectar source by bee colonies. Its superiority lies in that it may provide strong capability of local search and global optimization to effectively prevent the occurrence of local optimal solution.

In $\mathrm{ABC}$ algorithm, the bees are divided into employed bees, onlooker bees, and scout bees. The employed bees take charge of collecting honey in places with significant nectar, onlooker bees detect the locations of significant nectar, and scout bees are randomly let out to seek for new nectar sources when current nectar is almost exhausted. The bees exchange information about nectar quantity and locations by waggle dance; the quantity of honey in nectar is consistent with the quantity of employed bees. Feasible solutions of problems have a one-to-one correspondence relationship with the food sources, and the value of fitness function also 
TABLE 9: Summary and analysis of the calculation results.

\begin{tabular}{|c|c|c|c|c|c|c|}
\hline Indicators & Level & $h_{g}$ & $r_{b}$ & $r_{t}$ & $h_{r}$ & $d_{r}$ \\
\hline \multirow{9}{*}{$T_{\max }$} & $\mathrm{A}_{1}$ & 3118.245 & 3163.600 & 3115.660 & 3133.195 & 3133.940 \\
\hline & $\mathrm{A}_{2}$ & 3115.200 & 3110.030 & 3146.880 & 3122.650 & 3128.070 \\
\hline & $\mathrm{A}_{3}$ & 3132.435 & 3110.070 & 3117.470 & 3114.260 & 3119.065 \\
\hline & $\mathrm{A}_{4}$ & 3124.060 & 3125.775 & 3127.050 & 3127.685 & 3111.595 \\
\hline & $\mathrm{A}_{5}$ & 3128.595 & 3109.055 & 3111.470 & 3120.745 & 3125.865 \\
\hline & $S_{i}^{2}$ & 40.490 & 436.715 & 160.301 & 41.000 & 59.322 \\
\hline & $A_{\max }$ & 3132.435 & 3163.600 & 3146.880 & 3133.195 & 3133.940 \\
\hline & $A_{\min }$ & 3115.200 & 3109.055 & 3111.470 & 3114.260 & 3111.595 \\
\hline & $R$ & 17.235 & 54.545 & 35.410 & 18.935 & 22.345 \\
\hline \multirow{9}{*}{$S_{\max }$} & $\mathrm{A}_{1}$ & 866.220 & 814.870 & 838.895 & 823.385 & 823.765 \\
\hline & $\mathrm{A}_{2}$ & 838.060 & 861.355 & 841.465 & 858.200 & 964.145 \\
\hline & $\mathrm{A}_{3}$ & 857.330 & 845.290 & 838.275 & 816.975 & 800.020 \\
\hline & $\mathrm{A}_{4}$ & 825.300 & 831.970 & 842.600 & 893.060 & 811.835 \\
\hline & $\mathrm{A}_{5}$ & 800.090 & 833.520 & 825.775 & 795.390 & 787.240 \\
\hline & $S_{i}^{2}$ & 553.347 & 237.677 & 36.323 & 1181.832 & 4163.46 \\
\hline & $A_{\max }$ & 866.220 & 861.355 & 842.600 & 893.060 & 964.145 \\
\hline & $A_{\min }$ & 800.090 & 814.870 & 825.775 & 795.390 & 787.240 \\
\hline & $\mathrm{R}$ & 66.130 & 9.297 & 16.825 & 97.670 & 176.905 \\
\hline
\end{tabular}

TABLE 10: Significance test of each parameter.

\begin{tabular}{|c|c|c|c|c|c|c|}
\hline Indicators & Parameters & $S_{i}^{2}$ & $F$ & 0.05 critical value & 0.01 critical value & Significance \\
\hline \multirow{5}{*}{$T_{\max }$} & $h_{g}$ & 40.490 & 0.274 & 2.87 & 4.43 & \multirow{5}{*}{$※$} \\
\hline & $r_{b}^{g}$ & 436.715 & 2.959 & 2.87 & 4.43 & \\
\hline & $r_{t}$ & 160.301 & 1.086 & 2.87 & 4.43 & \\
\hline & $h_{r}$ & 41.000 & 0.278 & 2.87 & 4.43 & \\
\hline & $d_{r}$ & 59.322 & 0.402 & 2.87 & 4.43 & \\
\hline \multirow{5}{*}{$S_{\max }$} & $h_{g}$ & 553.347 & 0.448 & 2.87 & 4.43 & \multirow[b]{5}{*}{$※$} \\
\hline & $r_{b}^{g}$ & 237.677 & 0.193 & 2.87 & 4.43 & \\
\hline & $r_{t}$ & 36.323 & 0.029 & 2.87 & 4.43 & \\
\hline & $h_{r}$ & 1181.832 & 0.957 & 2.87 & 4.43 & \\
\hline & $d_{r}$ & 4163.460 & 3.373 & 2.87 & 4.43 & \\
\hline
\end{tabular}

has a one-to-one correspondence relationship with the quantity of nectar in food sources. ABC algorithm mainly consists of the following steps:

Step 1. a bee colony is produced randomly with the following equation:

$$
\begin{aligned}
& x_{i j}=x_{j}^{\min }+R^{*}\left(x_{j}^{\max }-x_{j}^{\min }\right), \\
& R^{*}=\operatorname{rand}(0,1),
\end{aligned}
$$

where $x_{i j}$ indicates $i^{\text {th }}$ bee in the bee colony; $j$ indicates dimension of the problem to be optimized; $x_{j}^{\max }$ and $x_{j}^{\min }$ are upper and lower limits of scope to be optimized.

Step 2. calculate the solution's probability;

Step 3. the bee colony starts the search for nectar sources:

$$
v_{i j}=x_{i j}+R^{*}\left(x_{i j}-x_{k j}\right) \text {, }
$$

where $v_{i j}$ indicates a new nectar source (a new solution) near current nectar source; $x_{i j}$ represents current solution; $x_{k j}$ is a random solution near current solution.
Step 4. judge and memorize the current best solution.

Step 5. repeat until finding the optimal solution.

The flowchart of this process is presented in Figure 11.

The quality of the nectar source will be evaluated by objective function values during the calculation. This paper uses $\mathrm{ABC}$ algorithm twice. In the first time, the objective function is the square root of difference between predicted values and original values of maximum temperature $T_{\max }$ and maximum stress $S_{\max }$ of piston. In the second time, the objective function is the square sum of difference between target values and calculated values of maximum temperature $T_{\max }$ and maximum stress $S_{\max }$. ABC is utilized to figure out the optimal parameters of piston by minimizing or maximizing the value of objective function. If the quality of the new nectar source is higher than that of previous one, the new source will be saved. The employed bees will transfer the information about the nectar source to the onlooker bees. The onlooker bees will determine location of the specific nectar based on the quality of the nectar source and a certain probability. The probability is calculated with following equation: 


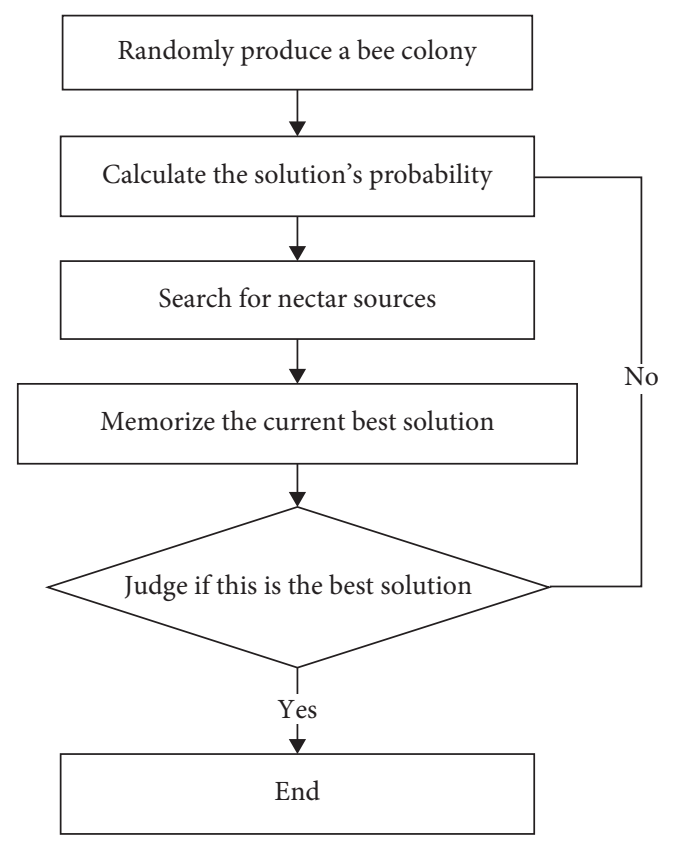

FIgURE 11: The flowchart of ABC algorithm.

$$
P=\frac{\mathrm{fit}_{i}}{\sum_{n=1}^{N} \mathrm{fit}_{n}},
$$

where $\mathrm{fit}_{i}$ is the fitness function corresponding to $i^{\text {th }}$ location of the nectar source. In the first time, using ABC algorithm, the locations represent the predicted values of maximum temperature $T_{\max }$ and maximum stress $S_{\max }$; in the second time, using $\mathrm{ABC}$ algorithm, the locations represent the calculated values of maximum temperature $T_{\max }$ and maximum stress $S_{\max }$.

After the honey at the specific nectar source location has been exhausted, the onlooker bees will give up the nectar source at the current location and release the scout bees to seek for new nectar sources. In this paper, it indicates that, in the first time, error between predicted values and original values of maximum temperature $T_{\max }$ and maximum stress $S_{\max }$ cannot be further reduced; in the second time, the square sum of difference between target values and calculated values of maximum temperature $T_{\max }$ and maximum stress $S_{\max }$ cannot be further increased. Such process may ensure the comprehensiveness of the overall algorithm and prevent the search from being trapped into the local optimal solution.

In ABC algorithm, there are two important parameters, i.e., $N_{i}$ and $M_{r}$, which will significantly influence the calculation results. $N_{i}$ represents the number of cycles before the scout bees were released, and $M_{r}$ represents the step length when searching for optimal solution. If the value of $N_{i}$ is small, the search may be stopped before the optimal solution is found; conversely, the solving efficiency of the algorithm may be low. If the value of $M_{r}$ is small, the solving efficiency of the algorithm may be low or even limited to the local optimal solution; conversely, the more optimal results may be skipped. It is clear that the values of two parameters will directly determine the validity and solving efficiency of ABC.
5.2. Fitting Equations. According to analysis in Section 3.4, for the two indicators (i.e., maximum temperature $T_{\max }$ and maximum stress $S_{\max }$ ), height $h_{g}$ of the intake and exhaust valve grooves at piston's top exerted a minor effect on them. Rounded corners $r_{b}$ and $r_{t}$ at the top and bottom of the grooves applied a more significant effect on the $T_{\max }$, while height $h_{r}$ and depth $d_{r}$ of the piston ring grooves applied a more significant effect on the $S_{\max }$. However, the degrees of effect exerted by 5 parameters on 2 indicators varied. In view of this, this paper proposed several different fitting equations (FEs) [39] and different fitting parameters settings to simulate their relationship in order to reduce the duration and cost of calculation while ensuring the accuracy.

According to Table 10, the order of the parameters ranked as per their effect on maximum temperature of piston $T_{\max }$ is the following: rounded corner $r_{b}$ at the bottom of the grooves, rounded corner $r_{t}$ at the top of the grooves, depth $d_{r}$ of ring grooves, height $h_{r}$ of the ring grooves, and groove depth $h_{g}$; the order of the parameters ranked as per their effect on maximum stress of piston $S_{\max }$ is as follows: depth $d_{r}$ of the ring grooves, height $h_{r}$ of the ring grooves, groove depth $h_{g}$, rounded corner $r_{b}$ at the bottom of the grooves, and rounded corner $r_{t}$ at the top of the grooves. During the fitting process, 1 to 5 parameters were selected as per their degree of effect by combining the FEs. The FEs presented in this paper include exponential equation, logarithmic equation, power exponential equation, exponential logarithmic equation, and polynomial equation. The FEs and their examples are shown in Table 11. In the examples, the number of fitting parameters for the indicator "temperature" is 3, which implies that the first three parameters with the greatest effect on the results were selected for calculation.

5.3. The ABC-OED-FE Method. Schemes for optimizing the parameters of the piston were determined with $A B C, O E D$, and $\mathrm{FE}$ in this paper (hence, the name is "ABC-OED-FE method"). The following steps were conducted:

1 Set the (initial) values of two parameters $N_{i}$ and $M_{r}$ in ABC algorithms

(2) Set the (initial) selection of FE

(3) Set the (initial) number of parameters in the FE

(4) Set the (initial) coefficients in FE

(5) Calculate the 5 parameters of piston with $\mathrm{ABC}$ algorithm combined above configuration

(6) Judge if that is the optimal combination of values of $\mathrm{ABC}$ parameters, FE, and the number of parameters in $\mathrm{FE}$

Since parameters indicated in Step 1 to Step 3 are interrelated, their values cannot be determined independently and were hence determined by calculating and analysing with orthogonal experiments method. For the detailed procedures of the ABC-OED-FE method, readers can refer to Figure 12.

5.4. Normalization of the Sample Data. The coefficients of the selected FE can be determined by the data calculated from 
TABLE 11: FEs and their examples.

\begin{tabular}{lcc}
\hline Equation & Functions & Examples \\
\hline Exponential & $y=a+b x^{c}$ & $y=a_{1}+a_{2} r_{b}^{a_{3}}+a_{4} r_{t}^{a_{5}}+a_{6} d_{r}^{a_{7}}$ \\
Logarithmic & $y=a+b \ln x$ & $y=a_{1}+a_{2} \ln r_{b}+a_{3} \ln r_{t}+a_{4} \ln d_{r}$ \\
Power exponential & $y=a e^{b x}$ & $y=a_{1} e^{\left(a_{2} r_{b}+a_{3} r_{t}+a_{4} d_{r}\right)}$ \\
Exponential logarithmic & $y=a+b e^{c x} \ln (x)$ & $y=a_{1}+a_{2} e^{\left(a_{3} r_{b}+a_{4} r_{t}+a_{5} d_{r}\right)} \ln \left(a_{6} r_{b}+a_{7} r_{t}+a_{8} d_{r}\right)$ \\
Polynomial & $y=(a x)^{2}$ & $y=\left(a_{1} r_{b}+a_{2} r_{t}+a_{3} d_{r}\right)^{2}$ \\
\hline
\end{tabular}

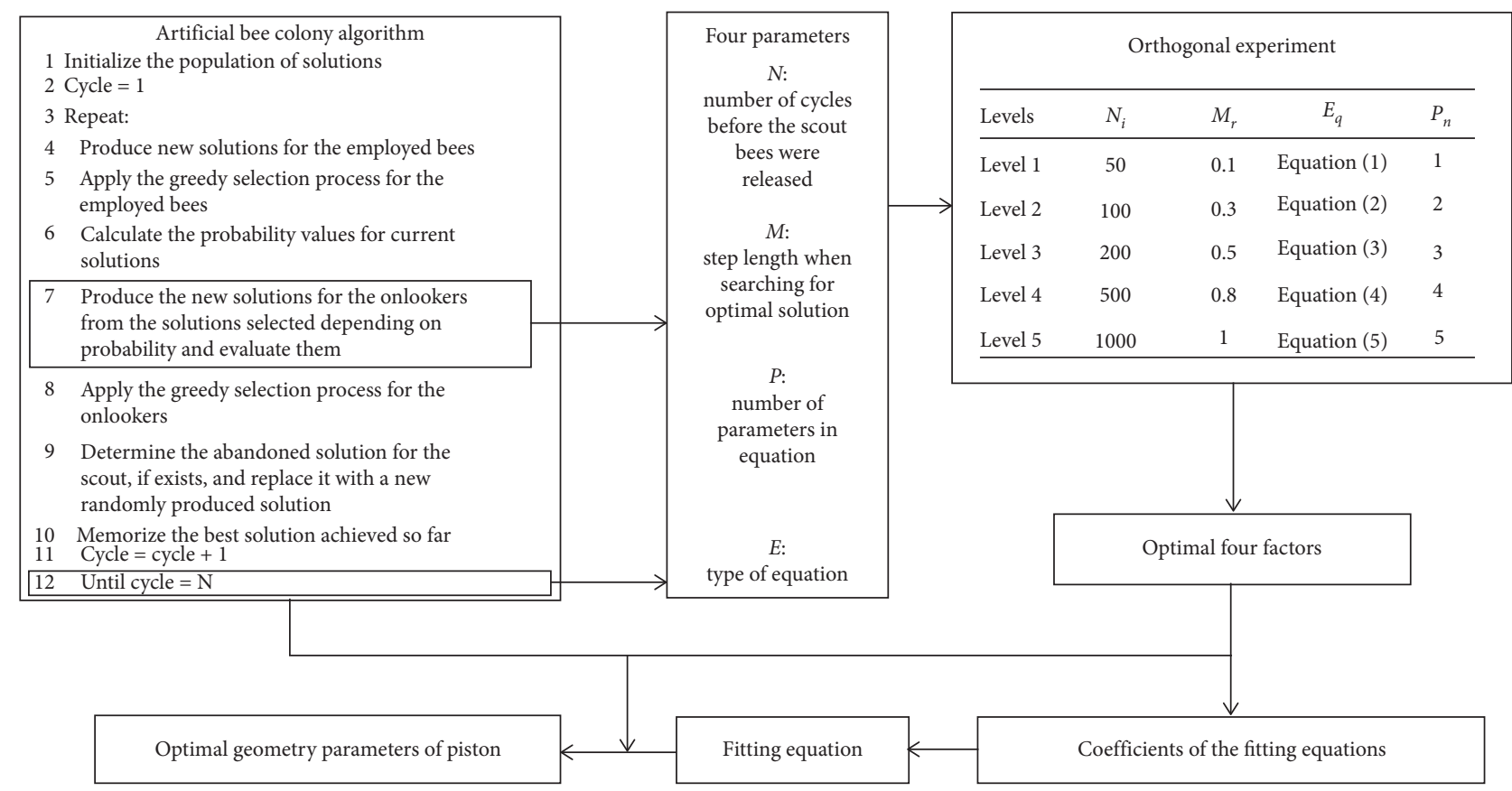

Figure 12: Procedures of ABC-OED-FE method.

the orthogonal experiments in Table 8. Before the analysis, all the sample data were normalized with following equation:

$$
X_{i}^{*}=\frac{X_{i}-X_{\min }}{X_{\max }-X_{\min }}
$$

where $X_{i}^{*}$ are the data after normalization, $X_{i}$ are initial data, and $X_{\max }$ and $X_{\min }$ are the maximum and minimum values in the data sets.

5.5. Determining Parameters. The optimal values for $N_{i}$ and $M_{r}$ corresponding to the equations to be fitted were not fixed. In addition, the number of parameters may also exert influence on the optimal values, increasing difficulties in determining the optimal conditions. This paper adopted the orthogonal experiment to determine the value of $N_{i}$ and $M_{r}$, options for equation fitting, and the number of parameters. The main factors include four indicators, i.e., the values of $N_{i}$ and $M_{r}$, the fitting equation $E_{q}$, and the number of parameters $P_{n}$.

Refer to Table 12 for each parameter and the corresponding levels. According to the table, this is an orthogonal experiment consisting of 4 factors and 5 levels and can be designed with an experiment table $L_{25}\left(5^{6}\right)$.
TABLE 12: The factors and the levels for the orthogonal experiment.

\begin{tabular}{lcccc}
\hline Levels & $N_{i}$ & $M_{r}$ & $E_{q}$ & $P_{n}$ \\
\hline Level 1 & 50 & 0.1 & $(1)$ & 1 \\
Level 2 & 100 & 0.3 & $(2)$ & 2 \\
Level 3 & 200 & 0.5 & $(3)$ & 3 \\
Level 4 & 500 & 0.8 & $(4)$ & 4 \\
Level 5 & 1000 & 1 & $(5)$ & 5 \\
\hline
\end{tabular}

Refer to Table 13 for the detailed experiment arrangements and calculation results.

For the experiment design, the target parameters to be solved are defined as follows:

$$
f_{t}=\frac{\sum\left[\left(T_{\mathrm{eq}}-T_{o}\right)^{2}+\left(S_{\mathrm{eq}}-S_{o}\right)^{2}\right]}{N_{s}},
$$

where $T_{\text {eq }}$ is the temperature value calculated with equation; $T_{o}$ is initial value of temperature; $S_{\text {eq }}$ is value of stress calculated with equation; $S_{o}$ is initial value of stress; $N_{s}$ is total number of samples.

Significance analyses [40] of the 4 indicators were made using the calculated values of $f_{t}$ and the results are shown in Table 14. According to the table, the significances of all the 
TABle 13: Experiment conditions and results.

\begin{tabular}{|c|c|c|c|c|c|}
\hline Numbers & $N_{i}$ & $M_{r}$ & $E_{q}$ & $P_{n}$ & $f_{t}$ \\
\hline 1 & 50 & 0.1 & 1 & 1 & 0.28690 \\
\hline 2 & 50 & 0.3 & 2 & 2 & 0.25553 \\
\hline 3 & 50 & 0.5 & 3 & 3 & 0.32210 \\
\hline 4 & 50 & 0.8 & 4 & 4 & 0.30773 \\
\hline 5 & 50 & 1.0 & 5 & 5 & 0.32243 \\
\hline 6 & 100 & 0.1 & 2 & 3 & 0.32187 \\
\hline 7 & 100 & 0.3 & 3 & 4 & 0.32488 \\
\hline 8 & 100 & 0.5 & 4 & 5 & 0.30178 \\
\hline 9 & 100 & 0.8 & 5 & 1 & 0.29642 \\
\hline 10 & 100 & 1.0 & 1 & 2 & 0.26953 \\
\hline 11 & 200 & 0.1 & 3 & 5 & 0.31139 \\
\hline 12 & 200 & 0.3 & 4 & 1 & 0.26083 \\
\hline 13 & 200 & 0.5 & 5 & 2 & 0.30260 \\
\hline 14 & 200 & 0.8 & 1 & 3 & 0.31060 \\
\hline 15 & 200 & 1.0 & 2 & 4 & 0.31400 \\
\hline 16 & 500 & 0.1 & 4 & 2 & 0.28220 \\
\hline 17 & 500 & 0.3 & 5 & 3 & 0.25532 \\
\hline 18 & 500 & 0.5 & 1 & 4 & 0.25861 \\
\hline 19 & 500 & 0.8 & 2 & 5 & 0.28804 \\
\hline 20 & 500 & 1.0 & 3 & 1 & 0.30510 \\
\hline 21 & 1000 & 0.1 & 5 & 4 & 0.27778 \\
\hline 22 & 1000 & 0.3 & 1 & 5 & 0.32056 \\
\hline 23 & 1000 & 0.5 & 2 & 1 & 0.32623 \\
\hline 24 & 1000 & 0.8 & 3 & 2 & 0.25671 \\
\hline 25 & 1000 & 1.0 & 4 & 3 & 0.27472 \\
\hline
\end{tabular}

TABLE 14: Significance analysis of the calculation indicators.

\begin{tabular}{lcccc}
\hline Indicators & $S_{i}^{2}$ & $F$ & 0.10 critical value & 0.05 critical value \\
\hline$N_{i}$ & 0.002 & 1.143 & 2.330 & 3.010 \\
$M_{r}$ & 0.001 & 0.571 & 2.330 & 3.010 \\
$E_{q}$ & 0.001 & 0.571 & 2.330 & 3.010 \\
$P_{n}$ & 0.003 & 1.714 & 2.330 & 3.010 \\
\hline
\end{tabular}

four indicators, i.e., $N_{i}, M_{r}, E_{q}$, and $P_{n}$, are not distinct, which implies that their influences on the results have slight differences. Given this, the results from orthogonal experiment can be used for the subsequent calculation and analysis.

By analysing the calculation results, we can find that the $17^{\text {th }}$ group of experiments generated calculation results with smallest $f$, as shown in Table 13. Detailed conditions of this experiment group are that $N_{i}$ is $500, M_{r}$ is $0.3, E_{q}$ is 5 , and $P_{n}$ is 3. It implies that, in ABC algorithm, if optimal solution is still not obtained after 500 cycles, the scout bees will seek for next target, step length searching for optimal solution is 0.3 , and, meanwhile, for maximum temperature $T_{\max }$ and maximum stress $S_{\max }$, polynomial equation is selected, and number of fitting parameters is 3 which implies that fitting parameters for the maximum temperature $T_{\max }$ are $r_{b}, r_{t}$, and $d_{r}$, and fitting parameters for the maximum stress $S_{\max }$ are $d_{r}, h_{r}$, and $h_{g}$.

Their FEs are as follows:

$$
\begin{aligned}
& T_{\mathrm{eq}}^{\prime}=\left(a_{1} r_{b}^{\prime}+a_{2} r_{t}^{\prime}+a_{3} d_{r}^{\prime}\right)^{2}, \\
& S_{\mathrm{eq}}^{\prime}=\left(a_{4} d_{r}^{\prime}+a_{5} h_{r}^{\prime}+a_{6} h_{g}^{\prime}\right)^{2} .
\end{aligned}
$$

Superscripts in the equation indicate that it is the normalized data.

Set $N_{i}=500, M_{r}=0.3$, solve the above two equations with $\mathrm{ABC}$ algorithm, and the calculation results are obtained as shown in Table 15.

Therefore, fitting equations for maximum temperature of piston $T_{\max }$ and maximum stress of piston $S_{\max }$ are as follows:

$$
\begin{aligned}
& T_{\mathrm{eq}}^{\prime}=\left(-0.4921 r_{b}^{\prime}-0.0824 r_{t}^{\prime}+1.179 d_{r}^{\prime}\right)^{2}, \\
& S_{\mathrm{eq}}^{\prime}=\left(-0.0534 d_{r}^{\prime}+0.4973 h_{r}^{\prime}-0.2503 h_{g}^{\prime}\right)^{2} .
\end{aligned}
$$

5.6. Optimizing Equation Set. With results calculated using ABC-OED-FE method, following objective function for piston optimization was established:

$$
f^{*}=\frac{\sum\left[\left(T_{\max }^{*}-T_{\mathrm{eq}}\right)^{2}+\left(S_{\max }^{*}-S_{\mathrm{eq}}\right)^{2}\right]}{N_{s}},
$$

where value of $T_{\text {max }}^{*}$ is 635.168, and value of $S_{\max }^{*}$ is 203.957 . These two values are the maximum results in Table 8 . 
TABLE 15: Values of each parameter.

\begin{tabular}{lccc}
\hline Parameters & Values & Parameters & Values \\
\hline$a_{1}$ & -0.9363 & $a_{4}$ & -0.0534 \\
$a_{2}$ & -0.0824 & $a_{5}$ & 0.4973 \\
$a_{3}$ & 1.1790 & $a_{6}$ & 0.2503 \\
\hline
\end{tabular}

ABC algorithm was adopted again to solve $f^{*}$ for its maximal values. Calculation results are shown in Table 16. Results show that maximum temperature $T_{e q}$ is $608.508 \mathrm{~K}$ and maximum stress $S_{e q}$ is $153.422 \mathrm{MPa}$.

5.7. Optimization Results. Suggestions for optimized piston with optimal temperature and stress state were provided through the above analysis: height $h_{g}$ of intake and exhaust valve grooves decreased to $5.82 \mathrm{~mm}$; smooth transition was added to groove bottom and radius of curvature $r_{b}$ set to $2.65 \mathrm{~mm}$; smooth transition was added to groove top and radius of curvature $r_{t}$ set to $2.25 \mathrm{~mm}$; height $h_{r}$ of piston ring groove decreased to $2.47 \mathrm{~mm}$, and depth $d_{r}$ of piston ring grooves increased to $6.15 \mathrm{~mm}$.

Geometric shape of optimized piston is shown in Figure 13.

By inspecting optimized piston with constraint conditions described in Section 3.1, the following aspects are revealed:

(1) Overall height and radius of the optimized piston maintain unchanged to prevent it from colliding with components such as cylinder head, valves, and connecting rod.

(2) Overall mass of optimized piston is $2.63 \mathrm{~kg}$ which is increased by $1.93 \%$ relative to mass of $2.58 \mathrm{~kg}$ before optimization. This can prevent interaction between piston and cylinder liner and connecting rod from exerting excessive forces.

(3) Displacement of optimized diesel engine is approximately invariant. Smooth corners may facilitate mixing of air and fuel, which exerts positive effect on combustion in the cylinder.

(4) Optimization of piston applies no effect on its normal functions and functions of other parts in the diesel engine.

\section{Analysis of Optimization Results}

6.1. Optimized Temperature Field. New finite element model of piston was established by combining optimized piston with thermal and mechanical boundary conditions. Temperature field of the optimized piston is shown in Figure 14.

According to the figure, maximum temperature of optimized piston is $607.56 \mathrm{~K}$ which is $16.11 \mathrm{~K}$ lower than that before optimization. The difference between original and after optimization piston is not too large, which can ensure preventing significant effect on combustion in the cylinder and power of the diesel engine, and is not too small, which proves the effectiveness of the optimization.
TABLE 16: Optimal values of the parameter.

\begin{tabular}{lccccc}
\hline Parameters & $r_{b}$ & $r_{t}$ & $d_{r}$ & $h_{r}$ & $h_{g}$ \\
\hline Values & 2.65 & 2.25 & 6.15 & 2.47 & 5.82 \\
\hline
\end{tabular}

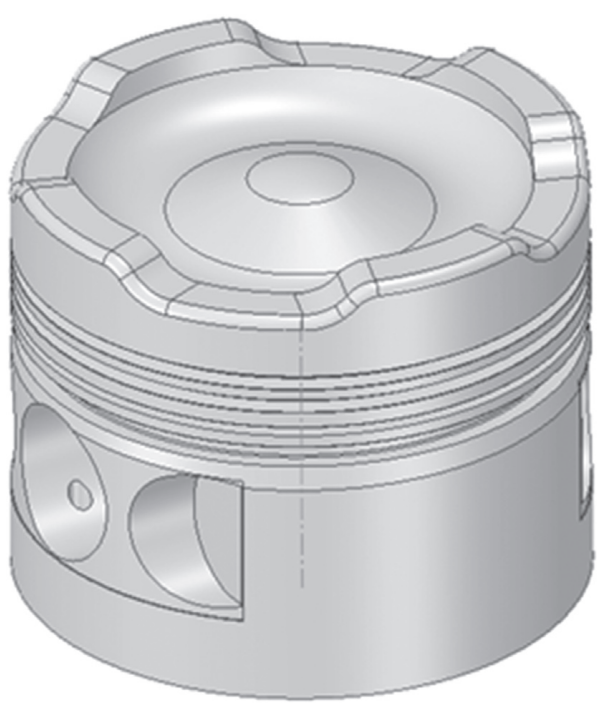

FIGURE 13: Geometric shape of optimized piston.

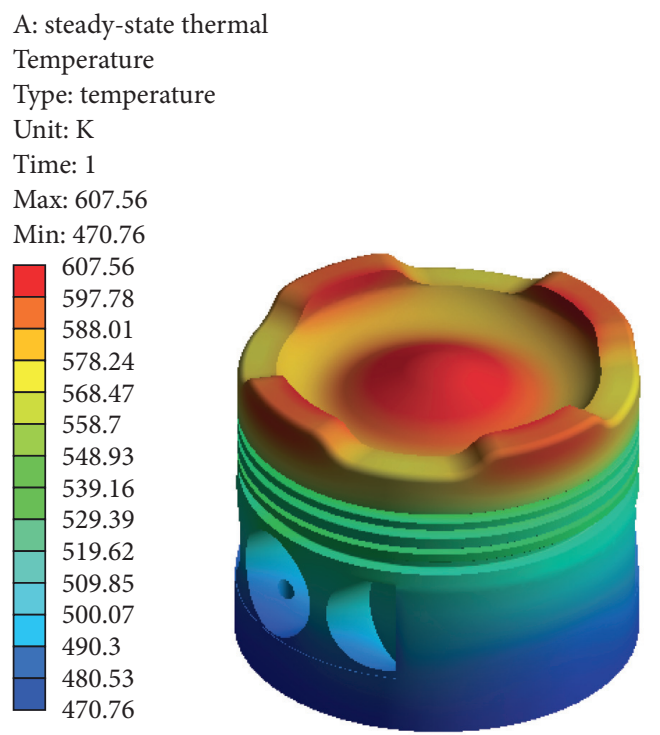

Figure 14: Temperature field of optimized piston.

6.2. Optimized Thermal-Mechanical Coupling Stress Field. Thermal-mechanical coupling stress field of optimized piston is shown in Figure 15. According to the figure, maximum thermal-mechanical coupling stress of optimized piston is $153.458 \mathrm{MPa}$ which is $15.212 \mathrm{MPa}$ lower than that before optimization. The declined magnitude is significant and overall load on the piston is also decreased.

Both thermal and mechanical load of optimized piston were decreased, which demonstrates favourable effectiveness of optimization and validity of the optimization algorithms. 


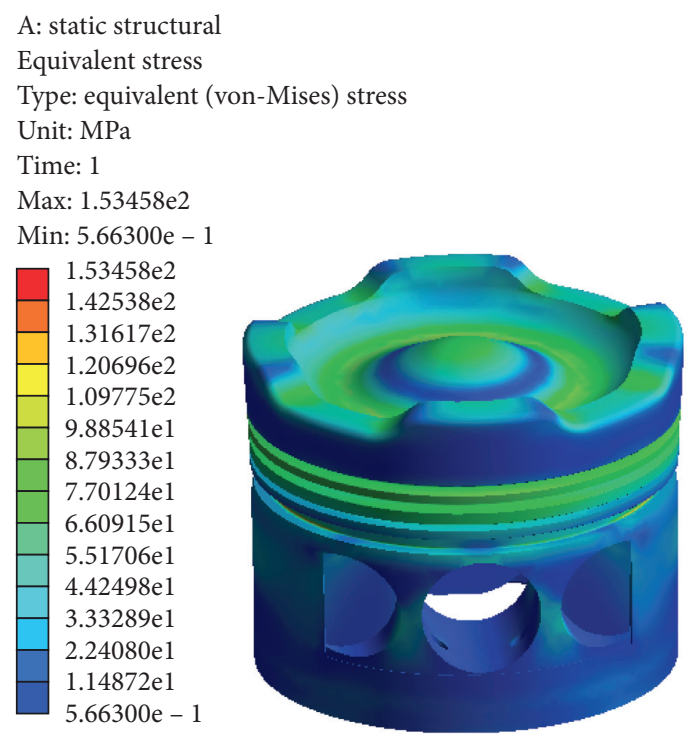

FIGURE 15: Thermal-mechanical coupling stress field of optimized piston.

TABLE 17: Comparison of the results.

\begin{tabular}{lccr}
\hline & Original condition & After optimization & Percentage improvement (\%) \\
\hline Maximum temperature (K) & 623.67 & 607.56 & 2.57 \\
Maximum stress (MPa) & 168.67 & 153.45 & 8.21 \\
\hline
\end{tabular}

6.3. Comparison of the Results. Table 17 shows the comparison of thermal and stress load of piston between original component and optimized component.

Table 17 illustrates, that compared to the original condition, the maximum temperature is $2.57 \%$ improved after optimization and the maximum stress is $8.21 \%$ improved after optimization.

\section{Conclusion}

Temperature field and thermal-mechanical coupling stress field of piston in diesel engine were calculated and analysed by finite element method, orthogonal experimental design method, and artificial bee colony algorithm. 5 parameters of the piston's geometric structure were optimized to decrease thermal and mechanical load exerted on piston. Main achievements of this article include the following:

(1) Boundary conditions of the piston calculating its thermal and mechanical load were calculated and analysed, using the model for combustion heat in cylinder and model for frictional heat between piston ring set and cylinder liner. Calculation results were verified with bench tests. The results provided boundary conditions for subsequent calculation of evaluation indicators: temperature and thermalmechanical coupling stress field of the piston.

(2) Two evaluation indicators of piston were calculated and analysed using established finite element model. Results show that serious thermal and mechanical load appeared at intake and exhaust valve grooves as well as ring grooves on the piston, which may lead to fatigue damage.

(3) Based on above calculation results and orthogonal experimental design method, law of effect on two evaluation indicators of piston exerted by 5 parameters at two positions, valve grooves at piston's top and the first piston ring groove, was discussed and analysed.

(4) Five FEs were proposed for fitting of correspondence relationship between the five optimization parameters and two evaluation indicators of piston. Two parameters for artificial bee colony algorithm and form of fitting equations were analysed and determined with ABC-OED-FE method.

(5) Coefficients of fitting equation and values of the 5 parameters under optimal piston temperature and stress were calculated and determined with artificial bee colony algorithm.

(6) Temperature field and thermal-mechanical coupling stress field of optimized piston were calculated and analysed. The results indicate that, after optimization, the maximum temperature of piston decreases to be $16.05 \mathrm{~K}$ and the maximum stress decreases to be 13.72 $\mathrm{MPa}$, which demonstrates favourable effectiveness of optimization and validity of the optimization algorithms.

In the method of ABC-OED-FE come up by this article, orthogonal experimental design and artificial bee colony algorithm were used repeatedly. Advantages of the two methods were fully exploited to study optimization of 
temperature and stress of piston in heavy-duty diesel engine. The optimization process was specific and explicit and may be applicable to improving and optimizing other hightemperature components in diesel engine. It is a method with fair extensibility. Study of this paper has important significance in ensuring efficient and reliable operation of high-temperature components, such as piston, cylinder head, cylinder liner, and gasket, in heavy-duty diesel engine.

In this article, we use the ABC-OED-FE method to optimize the geometrical parameters of piston. After optimization, both temperature and stress condition are relieved remarkable, which illustrate the good effectiveness of the optimization algorithm.

In the next research, the authors want to give some advice as follows:

(1) The researcher should focus on the temperature and stress condition of high temperature components in the diesel engine including but not limited to piston, cylinder sleeve, cylinder gasket, cylinder head, and values

(2) Some new algorithms should be adopted to solve the optimization work of high temperature components in diesel engine, including but not limited to neural network, support vector machine, and Bayesian probability model

(3) The applied areas of ABC-OED-FE method can be extended to every part in engineering computation; researchers should pay some attention to it

\section{Data Availability}

The raw/processed data required to reproduce these findings can be accessed through the tables in this article.

\section{Conflicts of Interest}

The authors declare that there are no conflicts of interest regarding the publication of this paper.

\section{References}

[1] J. Liu, Y. Dong, P. Wang, and Y. Liu, "Analysis and optimization of piston temperature field based on first order method," Vehicle Engine, vol. 3, pp. 30-34, 2016.

[2] Ö. Cihan, H. E. Doğan, O. A. Kutlar, A. Demirci, and M. Javadzadehkalkhoran, "Evaluation of heat release and combustion analysis in spark ignition Wankel and reciprocating engine," Fuel, vol. 261, Article ID 116479, 2020.

[3] Q. Wang, F. Wu, Y. Zhao, J. Bai, and R. Huang, "Study on combustion characteristics and ignition limits extending of micro free-piston engines," Energy, vol. 179, pp. 805-814, 2019.

[4] C. Yuan, H. Feng, Y. He, and J. Xu, "Combustion characteristics analysis of a free-piston engine generator coupling with dynamic and scavenging," Energy, vol. 102, pp. 637-649, 2016.

[5] S. Khan, R. Panua, and P. K. Bose, "Combined effects of piston bowl geometry and spray pattern on mixing, combustion and emissions of a diesel engine: a numerical approach," Fuel, vol. 225, pp. 203-217, 2018.
[6] H. Geng, Y. Wang, B. Xi et al., "Study on HCCI combustion improvement by using dual assisted compression ignition (DACI) on a hydraulic free piston engine fueled with methanol fuel," Applied Thermal Engineering, vol. 167, Article ID 114782, 2020.

[7] S. Khan, R. Panua, and P. K. Bose, "The impact of combustion chamber configuration on combustion and emissions of a single cylinder diesel engine fuelled with soybean methyl ester blends with diesel," Renewable Energy, vol. 143, pp. 335-351, 2019.

[8] Y. An, V. Raman, Q. Tang et al., "Combustion stability study of partially premixed combustion with low-octane fuel at low engine load conditions," Applied Energy, vol. 235, pp. 56-67, 2019.

[9] L. Xu, X.-S. Bai, C. Li, P. Tunestål, M. Tunér, and X. Lu, "Combustion characteristics of gasoline DICI engine in the transition from HCCI to PPC: experiment and numerical analysis,” Energy, vol. 185, pp. 922-937, 2019.

[10] A. Atmanli, E. Ileri, and N. Yilmaz, "Optimization of dieselbutanol-vegetable oil blend ratios based on engine operating parameters," Energy, vol. 96, pp. 569-580, 2016.

[11] B. Jia, R. Mikalsen, A. Smallbone, and A. P. Roskilly, "A study and comparison of frictional losses in free-piston engine and crankshaft engines," Applied Thermal Engineering, vol. 140, pp. 217-224, 2018.

[12] C. Fang, X. Meng, Y. Xie, C. Wen, and R. Liu, “An improved technique for measuring piston-assembly friction and comparative analysis with numerical simulations: under motored condition," Mechanical Systems and Signal Processing, vol. 115, pp. 657-676, 2019.

[13] M. Söderfjäll, H. M. Herbst, R. Larsson, and A. Almqvist, "Influence on friction from piston ring design, cylinder liner roughness and lubricant properties," Tribology International, vol. 116, pp. 272-284, 2017.

[14] R. Turnbull, N. Dolatabadi, R. Rahmani, and H. Rahnejat, "An assessment of gas power leakage and frictional losses from the top compression ring of internal combustion engines," Tribology International, vol. 142, Article ID 105991, 2020.

[15] H. Li, H. Liu, S. Jiang, and J. Chang, "A study on the oil transport in piston skirt-cylinder liner under fully flooded conditions using improved SPH simulations," Engineering Analysis with Boundary Elements, vol. 109, pp. 176-186, 2019.

[16] A. Azzi, A. Maoui, A. Fatu, S. Fily, and D. Souchet, "Experimental study of friction in pneumatic seals," Tribology International, vol. 135, pp. 432-443, 2019.

[17] Q. Xu, S. Li, Y. Lian, and S. Wang, "Strength analysis and structural improvement of new cam engine piston," Journal of Wuhan University (Engineering Edition), vol. 52, no. 3, pp. 270-282, 2019.

[18] Y. Wang, L. Wu, S. Liu, M. Li, and Y. Cui, "Fretting fatigue optimization of piston skirt top surface of marine diesel engine," Proceedings of the Institution of Mechanical Engineers, Part C: Journal of Mechanical Engineering Science, vol. 233, no. 4, pp. 1453-1469, 2018.

[19] Q. Zhaoju, L. Yingsong, Y. Zhenzhong, D. Junfa, and W. Lijun, "Diesel engine piston thermo-mechanical coupling simulation and multidisciplinary design optimization," Case Studies in Thermal Engineering, vol. 15, Article ID 100527, 2019.

[20] T. Zhang, J. Eismark, K. Munch, and I. Denbratt, "Effects of a wave-shaped piston bowl geometry on the performance of heavy duty Diesel engines fueled with alcohols and biodiesel blends," Renewable Energy, vol. 148, 2019. 
[21] R. Sadiq Y and R. C. Iyer, "Experimental investigations on the influence of compression ratio and piston crown geometry on the performance of biogas fuelled small spark ignition engine," Renewable Energy, vol. 146, pp. 997-1009, 2020.

[22] H. Chen, P. Hofbauer, and J. P. Longtin, "Multi-objective optimization of a free-piston Vuilleumier heat pump using a genetic algorithm," Applied Thermal Engineering, vol. 167, Article ID 114767, 2020.

[23] M. Channappagoudra, K. Ramesh, and G. Manavendra, "Comparative study of standard engine and modified engine with different piston bowl geometries operated with B20 fuel blend," Renewable Energy, vol. 133, pp. 216-232, 2019.

[24] X.-B. Liu, M. Pang, Z.-G. Zhang, J.-S. Tan, G.-X. Zhu, and M.-D. Wang, "Numerical simulation of stress field for laser thermal loading on piston," Optics \& Laser Technology, vol. 44, no. 5, pp. 1636-1640, 2012.

[25] N. Yilmaz, E. Ileri, A. Atmanli et al., "Predicting the engine performance and exhaust emissions of a diesel engine fueled with hazelnut oil methyl ester: the performance comparison of response surface methodology and LSSVM," Journal of Energy Resources Technology, vol. 138, Article ID 52206, 2016.

[26] B. Yuksel, "Response surface methodology based optimization of diesel-n-butanol -cotton oil ternary blend ratios to improve engine performance and exhaust emission characteristics," Energy Conversion \& Management, vol. 90, pp. 383-394, 2015.

[27] E. Ileri, A. D. Karaoglan, and A. Atmanli, "Response surface methodology based prediction of engine performance and exhaust emissions of a diesel engine fuelled with canola oil methyl ester," Journal of Renewable \& Sustainable Energy, vol. 5, p. 3622, 2013.

[28] Z. Zhang, C. Guo, Y. Song et al., "Research on the engine combustion characteristics of a free-piston diesel engine linear generator," Energy Conversion and Management, vol. 168, pp. 629-638, 2018.

[29] Y. Dong, J. Liu, Y. Liu et al., “A RBFNN \& GACMOO-based working state optimization control study on heavy-duty diesel engine working in plateau environment," Energies, vol. 13, no. 1 , p. 279,2020

[30] M. Söderfjäll, A. Almqvist, and R. Larsson, "Component test for simulation of piston ring-cylinder liner friction at realistic speeds," Tribology International, vol. 104, pp. 57-63, 2016.

[31] X. Meng, C. Fang, and Y. Xie, "Transient tribodynamic model of piston skirt-liner systems with variable speed effects," Tribology International, vol. 94, pp. 640-651, 2016.

[32] Y. Qian, Q. Hu, Z. Li et al., "An experimental investigation on the evaporation characteristics of lubricating oil film in different grooves," International Communications in Heat and Mass Transfer, vol. 110, Article ID 104413, 2020.

[33] P. Wang, R. Liang, Y. Wang, Y. Yu, J. Zhang, and M. Liu, “The numerical investigation of heat transfer enhancement of copper-oil and diamond-oil nanofluids inside the piston cooling gallery," Powder Technology, vol. 320, pp. 313-324, 2017.

[34] Y. Dong, J. Liu, Y. Liu et al., "The optimization research of diesel cylinder gasket parameters based on hybrid neutral network and improved grey wolf algorithm," Mathematical Problems in Engineering, vol. 2020, Article ID 3718174, 16 pages, 2020.

[35] W.-c. Tang, Z.-y. Piao, J. Zhang, S.-y. Liu, and L.-j. Deng, "Effect of trace elements on the pinhole fatigue-resistance of gasoline Al-Si piston alloy," Engineering Failure Analysis, vol. 108, Article ID 104340, 2020.
[36] S. Manigandan, A. E. Atabani, V. K. Ponnusamy, A. Pugazhendhi, P. Gunasekar, and S. Prakash, "Effect of hydrogen and multiwall carbon nanotubes blends on combustion performance and emission of diesel engine using Taguchi approach,” Fuel, vol. 276, Article ID 118120, 2020.

[37] Z. J. Hu, Q. Li, Z. Y. Li, and Q. Li, "Orthogonal experimental study on high frequency cascade thermoacoustic engine," Energy Conversion and Management, vol. 49, no. 5, pp. 1211-1217, 2008.

[38] D. Karaboga and B. Basturk, "A powerful and efficient algorithm for numerical function optimization: artificial bee colony (ABC) algorithm," Journal of Global Optimization, vol. 39, no. 3, pp. 459-471, 2007.

[39] M. Peng, A. V. Nguyen, J. Wang, and R. Miller, "A critical review of the model fitting quality and parameter stability of equilibrium adsorption models," Advances in Colloid and Interface Science, vol. 262, pp. 50-68, 2018.

[40] C. Xu, W. Nie, S. Yang et al., "Numerical simulation of the multi-index orthogonal experiments on the spray dust-settling devices," Powder Technology, vol. 371, pp. 217-230, 2020. 